\title{
The Parallel Universe and the \\ Pensive Practitioner: Reflections on \\ Screendance Prompted by Laura \\ Mulvey's "Pensive Spectator"
}

Kyra Norman

7

he title of this issue of the International Journal on Screendance, "Scaffolding the Medium," suggests an opportunity to investigate structures and materials that might support and underpin current thinking and practice in screendance. In this spirit, the material explored here is the final chapter of British feminist film theorist Laura Mulvey's book, Death 24x a Second: Stillness and the Moving Image, published in 2006. This closing chapter is titled "The Pensive Spectator."

The Oxford English Dictionary gives the following definition of "pensive": "engaged in, involving, or reflecting deep or serious thought."1 Mulvey's chapter is concerned with the pause for reflection on the screen image that new technologies have enabled. Since Mulvey's text is readily available elsewhere, rather than reproduce the chapter in its entirety here, I have invited two artists-Miranda Pennell and Augusto Corrieri-to take an appropriately pensive approach: to reflect on their own practice, and/ or experience of spectatorship, by way of Mulvey's writing (and vice versa). Following these new writings, which offer original insights into the artists' practices, as well as reflecting themes from the chapter in question, I will indicate some of the ideas and questions, which I feel the Mulvey chapter raises for those of us engaged in screendance.

I hope that this might serve as a productive point of departure for screendance artists, curators, researchers, producers and audiences, and that as a whole, these writings will prompt further reading and discussion of Mulvey's writing in the context of our field.

\section{Notes}

1. Oxford English Dictionary Online, adj. n. "pensive." ww.oed.com/viewdictionaryentry/Entry/140265. 